\title{
Assessment of urban growth using Shannon's Entropy Index: A case study of Chennai, Detroit of India
}

\author{
N. Shenbagaraj* \\ Centre for Aerospace Research, Madras Institute of Technology, Chennai (Tamil Nadu), \\ India

\section{Naresh Kumar} \\ Centre for Aerospace Research, Madras Institute of Technology, Chennai (Tamil Nadu), \\ India \\ J. Leo Stalin \\ Centre for Aerospace Research, Madras Institute of Technology, Chennai (Tamil Nadu), \\ India \\ *Corresponding author. E-mail: shenba.gis2009@gmail.com
}

\begin{abstract}
The Remote Sensing (R/ S) and Geographical Information System (GIS) play a vital role to evaluate and study the urban expansion pattern. In this study, the Chennai city was selected to perform the urban sprawl study. Five different periods of satellite imageries for the time elapsed between 1994 and 2016 were used. The main aim of this paper was to identify the urban sprawl of Chennai as a patterning process. The extended areas of urban in the period of 1994, 2001, 2006, 2011 and 2016 were extracted by the sub-pixel classification method from the satellite imageries. Furthermore, Shannon's entropy index was used for assessing urban expansion. The findings of this study proved that Chennai city has sprawled by urban expansion during the period between 1994 and 2016. Likewise, the dispersion rate of urban sprawl for the periods of 1994, 2001, 2006, 2011 and 2016 were $0.671,0.679,0.688,0.693$ and 0.695 respectively. Consequently, this uncontrolled dispersed urban development had resulted in the study area losses their green space.
\end{abstract}

Keywords: Detroit of India, Geographical Information System (GIS), Remote Sensing $(\mathrm{R} / \mathrm{S})$, Shannon's entropy, Sub-pixel classification, Urban sprawl

\section{INTRODUCTION}

At present, the developed and developing countries' cities are experienced prompt change. They are increasing in area, population density and at the same time they are obtaining a new character as their people execute new tasks in the physical environment, that increasingly reflect the use of new technology (Allefsen, 1962; Milap Punia and Laxman Singh 2012). Prompt expansion of urban area creates a huge level of changes in the landscape have been recently observed in many developing countries including India as a result of rapid economic advancements (Yeh and Li, 2001; Mohapatra et al., 2014; Derya Ozturk, 2017). It is considered as the greatest significant changes in Land Use and Land Cover (LU/ LC) changes (Weng, 2001). The result of a large scale of urban sprawl, the surrounding natural land parcels such as agricultural fields, forests or wetlands were encroached (Xu et al., 2000).Changes of these other natural land use features into these impervious built-up lands can put important impacts on the

\section{Article Info}

DOI: 10.31018/jans.v11i2.2037

Received: March 10, 2019

Revised: April 6, 2019

Accepted: April 15, 2019

\section{How to Cite}

Shenbagaraj, N. et al. (2019). Assessment of urban growth using Shannon's Entropy Index: A case study of Chennai, Detroit of India. Journal of Applied and Natural Science, 11(2): 281- 284 https://doi.org/10.31018/ jans.v11i2.2037 
The former researchers, in their studies different methods were applied for zone divisions to calculate the entropy index. For example, the city center based created the buffer zones; pie selection based dividing the study area into zones and administrative boundary depends on dividing the zones. In the present study, the Chennai city was divided into five zones based on the Taluk boundaries. The core aim of this study was to show the combined use of R/ S and GIS with Shannon's entropy in addressing a basic urban sprawl issue of the Chennai city. The precise objective is to evaluate the urban growth patterns in the studied area in the period between 1994 and 2016.

\section{MATERIALS AND METHODS}

Study area: Chennai city (Detroit of India), the capital of the Tamil Nadu was selected as a study area in this study. It is the main economic, commercial, financial and business centre of Tamil Nadu. Chennai city is geographically located in between $80^{\circ} 10^{\prime} 5.079 " \mathrm{E}$ to $80^{\circ} 18^{\prime} 39.522 " \mathrm{E}$ Longitude and $12^{\circ} 56^{\prime} 56.547^{\prime \prime} \mathrm{N}$ to $13^{\circ} 8^{\prime} 17.583^{\prime \prime} \mathrm{N}$ latitude along the Bay of Bengal coast in the western part of the study area. The study area is divided into five Taluk namely: Egmore - Nungambakkam, Mambalam - Guindy, Mylapore - Triplicane, Perambur - Purasawalkam and Fort - Tondiarpet as shown in Fig. 1.

$\mathrm{R} / \mathrm{S}$ and GIS are a unique phenomenon that can play a major role in effective and well-organized mapping and monitoring a vast change of landuse and land-cover. Thus, to achieve the abovementioned aim the following methodology has been adopted. For this study, different sensors of Landsat satellite imageries have been used. Subpixel classification technique has been employed to built-up area classification for every period of satellite images. It deals with performing feature in the classification by breaking the pixel into more pixels based on the unmixed spectral by identifying the abundance of classes using a fuzzy logic algorithm. Actual built-up area calculated for every period which was used to compute the Shannon's Entropy Index. It was computed for understanding urban growth. It helps to determine whether the growth and urban expansion was more dispersal (sprawl) or compact in nature.

Shannon's Entropy Index is given below

$$
\mathbf{H}_{\mathrm{n}}^{1}=-\sum \mathrm{Pi}^{\star} \log \mathrm{Pi}
$$

$$
\mathbf{H}_{\mathrm{n}}^{\mathbf{1}}=\sum \mathrm{Pi}^{*} \log (1 / \mathrm{Pi})
$$

Where,

$\mathrm{Pi}$ is the proportion of the built-up value in the ith Zone (Taluk)

$\mathrm{n}$ represents the total number of Taluks

$\log n$ represents the maximum limit of entropy i.e. equal to $\log 5=0.69897$.

The outcome of Shannon's Entropy index ranges between 0 and $\log (n)$, where the index ranges are closer to zero indicates the urban distribution is compact else if the values are nearer to $\log n$ represents the spreading of sprawl. Values of entropy index closer to log $n$ disclose the dispersion of the settlement area, which denotes the incidence of urban expansion and heterogeneity of other land uses. The change of entropy values in every period represents land development is toward a divergent or compact pattern. The detailed workflow of this study is shown in Fig. 2.

\section{RESULTS AND DISCUSSION}

The five different periods of satellite images were classified into two classes. The first one is the built -up area and another one is non-built up area. The former researchers in their studies supervised classification technique was employed for satellite image classification process (Jyotishman Deka et al., 2012; Abdelkader El Garouani et al., 2017; James Magidi and Fethi Ahmed, 2017). In the present study, the sub-pixel classification method was adopted for classifying the built-up areas. Fig. 3 shows the classified built-up area for the year of 1994, 2001, 2006, 2011 and 2016. It clearly represented the urban growth of Chennai city in differ-
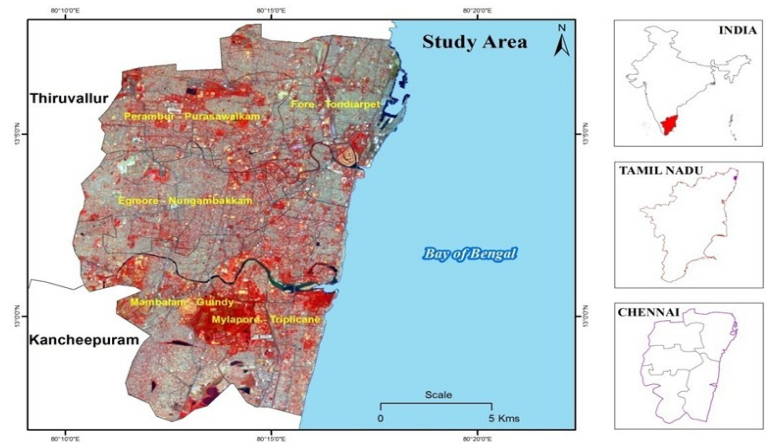

Fig. 1. Study area: Chennai City showing the Taluk boundary with Satellite image background.

Table 1. The Shannon's Entropy Index of Egmore - Nungambakkam, Mambalam - Guindy, Mylapore - Triplicane, Perambur - Purasawalkam and Fort - Tondiarpet Taluks.

\begin{tabular}{llllll}
\hline Taluk & $\mathbf{1 9 9 4}$ & $\mathbf{2 0 0 1}$ & $\mathbf{2 0 0 6}$ & $\mathbf{2 0 1 1}$ & $\mathbf{2 0 1 6}$ \\
\hline Egmore - Nungambakkam & 0.133 & 0.141 & 0.142 & 0.141 & 0.140 \\
Mambalam - Guindy & 0.132 & 0.132 & 0.129 & 0.138 & 0.142 \\
Mylapore - Triplicane & 0.114 & 0.114 & 0.133 & 0.132 & 0.132 \\
Perambur - Purasawalkam & 0.134 & 0.134 & 0.130 & 0.130 & 0.131 \\
Fort Tondiarpet & 0.158 & 0.158 & 0.156 & 0.152 & 0.150 \\
Total & $\mathbf{0 . 6 7 1}$ & $\mathbf{0 . 6 7 9}$ & $\mathbf{0 . 6 8 8}$ & $\mathbf{0 . 6 9 3}$ & $\mathbf{0 . 6 9 5}$ \\
\hline
\end{tabular}


Shenbagaraj, N. et al. / J. Appl. \& Nat. Sci. 11(2): 281- 284 (2019)

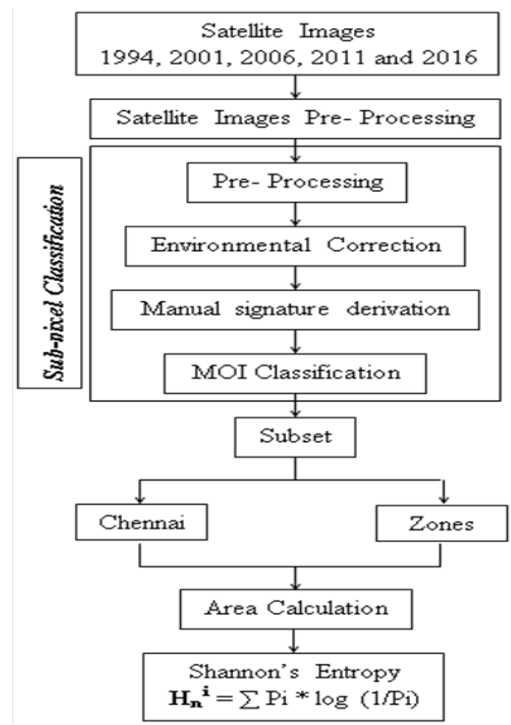

Fig. 2. Detailed workflow for assessing the Urban sprawl of Chennai city.

ent periods. In the sub-pixel classification method, a pixel was sub-divided into eight classes based on the occupied percentage of the urban area. In this classification method, only 20-29, 30-39, 40$49,50-59,60-69,70-79,80-89$ and 90 to 100 percent of occupied urban area were assessed which is represents in light yellow to dark red colour in Fig. 3. The actual built-up area of study area calculated from eight classes and then combined to obtain a total built-up area. Taluk-wise calculated entropy index and year wise graphical representation or Shannon's entropy index of the study area are shown in Table 1 and Fig. 4 respectively. It clearly demonstrates the urban sprawl was gradually increased from 1994 to 2016.

The calculated Shannon's entropy index of Chennai District for the year of 1994, 2001, 2006, 2011 and 2016 is $0.671,0.679,0.688,0.693$ and 0.695 respectively. The above mentioned all periods of the index value was nearly equal to the upper limit of the entropy value 0.69897 . It is the greatest evidence for the urban expansion of the Chennai city comes under the more dispersal.

\section{Conclusion}

Chennai city had experienced a rapid rate of urban growth over the period of time. This study had taken efforts to identify the urban sprawl for the period between 1994 and 2016. The spatial urban expansion dynamics had efficiently captured by R/ $S$ and GIS techniques using entropy index approach. In this study, satellite imageries play a vital role in mapping and quantifying the temporal urban extension area. The proposed methodology of classification in this study helps to get a more accurate built-up area. For all periods, calculated Shannon's entropy index of Chennai city is gradually increased indicating the greatest evidence for

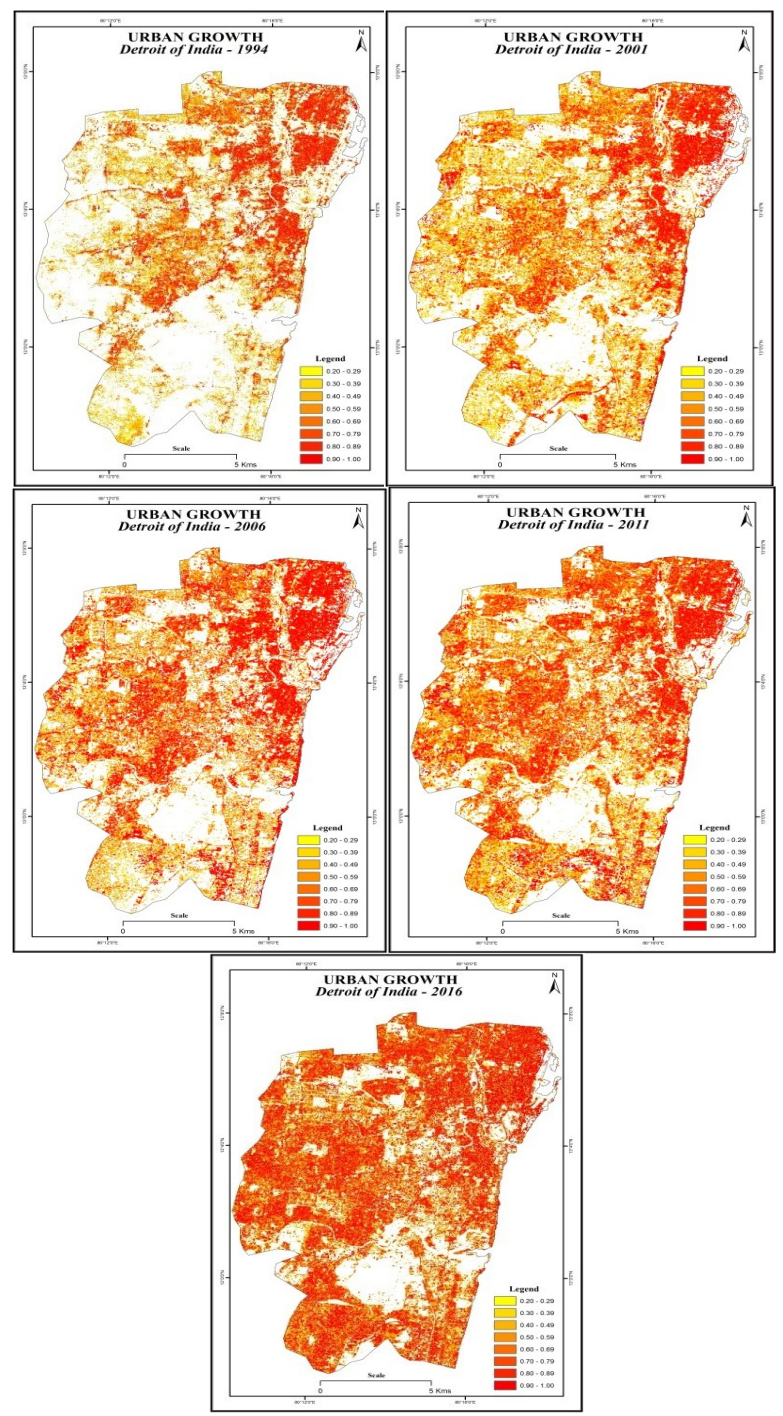

Fig. 3. Sub-pixel classification outcome for the year of 1994, 2001, 2006, 2011 and 2016.

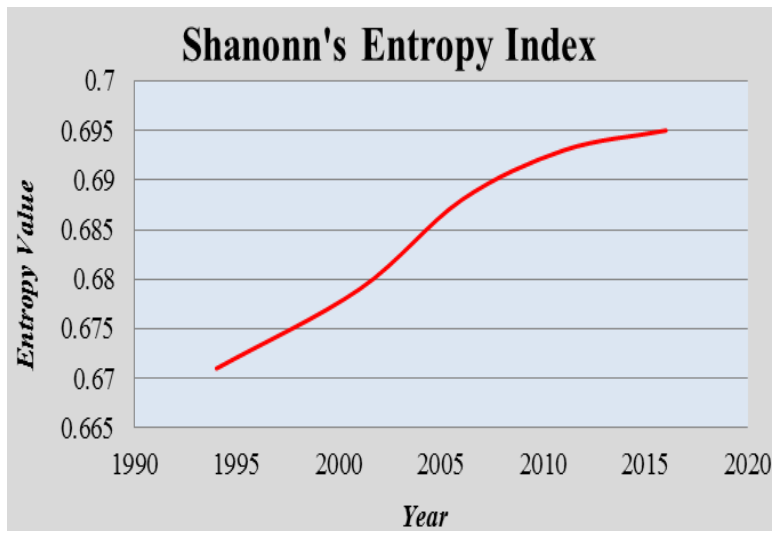

Fig. 4. Different periods of Shannon's Entropy Index of the Chennai city.

urban sprawl in the Chennai city. It will automatically affect the other most important factors of LU/ LC. The outcome of this study helps in taking proper measure of sustainable development. 


\section{REFERENCES}

1. Allefsen, R.A. (1962). City hinterland relationship in India. India's In R. Turner (Ed.), Urban future, Barkerly: University of California Press, $94-116$.

2. Derya Ozturk. (2017). Assessment of Urban sprawl using Shannon's Entropy and Fractal Analysis: A Case Study of Atakum, Ilkadim and Canik (Samsum, Turkey), Journal of Environmental Engineering and Landscape Management, 25 (3): 264-276, DOI: 10.3846/16486897.2016.1233881.

3. Guindon, B., and Zhang, Y., (2009). Automated Urban Delineation from Landsat Imagery Based on Spatial Information Processing, Photogrammetric Engineering and Remote Sensing, 75(7), 845-858.

4. Jyotishman Deka, Om Prakash Tripathi and Mohamed Latif Khan (2012), Urban growth trend analysis using Shannon Entropy approach - A case study in North-East India, International Journal of Geomatics and Geosciences, 2(4): 1062-1068, DOI: $10.1007 /$ s12524-011-0141-z.

5. MilapPunia and Laxman Singh. (2012). Entropy Approach for Assessment of Urban Growth: A Case Study of Jaipur, India, Journal of Indian Society of Remote Sensing, 40 (2): 231-244, DOI: 10.1007/ s12524-011-0141-z.

6. S. N. Mohapatra., Padmini Pani., and Monika Sharma. (2014). Rapid Urban Expansion and Its Implications on Geomorphology: A Remote Sensing and GIS Based Study, Geography Journal, Article ID 361459, 1-10, DOI: $10.1155 / 2014 / 361459$.

7. Soffianian, A., Nadoushan, M., A. Yaghmaei, L., and Falahatkar, S. (2010). Mapping and Analyzing Urban Expansion Using Remotely Sensed Imagery in Isfahan, Iran, World Applied Sciences Journal, 9 (12), 1370-1378.
8. Sudhira, H.S., Ramachandra, T.V., and Jagadish, K.S. (2004). Urban sprawl: metrics, dynamics and modeling using GIS, International Journal of Applied Earth Observation and Geoinformation, 5(1): 29-39, DOI: 10.1016/j.jag.2003.08.002.

9. Vivek Garg and Alok Sharma. (2018). Urban Sprawl Analysis Using GIS Applications for Jabalpur City, International Research Journal of Engineering and Technology (IRJET), 5(5):4171-4176

10.Weng, Q. (2001). A remote sensing? GIS evaluation of urban expansion and its impact on Surface Temperature in the Zhujiang Delta, China, International Journal of Remote Sensing, 22(10), 1999-2014, DOI: 10.1080/713860788.

11.Xu, H., Wang, X., and Xiao, G. (2000). A remote sensing and GIS integrated study on urbanization with its impact on arable lands: Fuqing City, Fujian Province, China, Land Degradation \& Development, 11(4), 301-314, DOI:10.1002/1099-145X(200007/08) 11:4\%3C301::AID-LDR392\%3E3.0.CO;2-N.

12.Yeh, A.G., and Li, X. (2001). Measurement and Monitoring of Urban Sprawl in a Rapidly Growing Region Using Entropy, Photogrammetric Engineering and Remote Sensing, 67(1):83-90.

13.James Magidi and Fethi Ahmed (2017). Assessing Urban Sprawl using Remote Sensing and Landscape Metrics: A Case Study of City of Tshwane, South Africa (1984-2015), The Egyptian Journal of Remote Sensing and Space Sciences, 1-12, DOI: 10.1016/ j.ejrs.2018.07.003.

14.Abdelkader El Garouani., David J. Mulla., Said EI Garouani., Joseph Knight (2017) Analysis of Urban Growth and Sprawl from Remote Sensing Data: Case of Fez, Morocco, International Journal of Sustainable Built Environment, 6 (1): 160-169, DOI: 10.1016/j.ijsbe.2017.02.003. 